Coupled models simulate realistically the world's most intense short-range climate fluctuation and have yielded the first successful short-range climate forecasts. They required a high resolution over oceanic regions in describing the unstable interactions between the ocean and the atmosphere.

\title{
Modelling the EI Niño - Southern Oscillation
}

The term El Niño was originally used by Peruvian fisherman at the end of the last century to describe the seasonal warming of the surface waters off the coast of Peru which occurred around Christmas time, marking the end of the fishing season (EI Niño, the "Christmas child" in Spanish). The term EI Niño is used today to refer to the large-scale warming of the entire tropical Pacific [1] which occurs every four years on the average and typically involves the surface waters increasing in temperature by $2^{\circ} \mathrm{C}$ (Fig. 1a). However, the interannual variations in sea surface temperature (SST) show a pronounced oscillatory behaviour, with positive and negative swings (Fig. 1c). By analogy, the cold phases are sometimes referred to as La Niña.

An oscillation - called the Southern Oscillation - was identified by Walker in 1923 while studying rainfall variations over India. It can be described in terms of a seesaw in the global sea level pressure field, with opposite changes in the eastern and western hemispheres (Fig. 1b). Bjerknes in 1969 was the first to propose that the El Niño and the Southern Oscillation phenomena are closely related, representing simply different aspects of the same coupled mode in the ocean-atmosphere system. Anomalously high sea-surface temperatures in the tropical Pacific coincide with, for instance, negative swings in the atmospheric pressure gradient at sea level (the Southern Oscillation Index, SOI), and vice versa (Fig. 1c). Since the SOI measures the pressure difference between the two centres of action of the Southern Oscillation, anomalies in the SOI are associated with changes in the strength of the Pacific trade winds. It was Bjerknes who realized that variations in the trade-wind field are crucial for generating large-scale anomalies in the Pacific's sea surface temperature, and that local air-sea heat exchange is of minor importance.

Mojib Latif is a Senior Scientist with the MaxPlanck-Institut für Meteorologie, Bundestrasse 55, D-20146 Hamburg. He studied meteorology at the University of Hamburg and received his Ph.D. in oceanography from the same university in 1987 while working at the MPI, which he joined in 1982. He presently co-chairs the Tropical Ocean Global Atmosphere project's Numerical Experimentation Group and is the Editor of Monthly Weather Review.

J. David Neelin is an Associate Professor with the Department of Atmospheric Sciences, University of California, Los Angeles, CA 90024, USA, which he joined after working as a postdoc at the Massachusetts Institute of Technology. He grew up in Canada and studied at Princeton University where he was awarded a Ph.D while working at the Geophysical Fluid Dynamics Laboratory.

\section{Mojib Latif ${ }^{1}$ and J. David Neelin ${ }^{2}$}

\author{
${ }_{1}^{1}$ Max-Planck-Institut für Meteorologie, Hamburg, Germany \\ 2 Department of Atmospheric Sciences, University of California-Los Angeles, USA
}

The El Niño-Southern Oscillation (ENSO) phenomenon is the strongest natural climate fluctuation occurring on the shortrange climatic time-scale of a few months to several years that we know of. Although originating in the tropical Pacific, it influences not only regional but also global climate. For instance, variations in major rainfall systems around the world [4] are well documented (see insert). Aside from its global climate anomalies, ENSO has a significant impact on ecosystems in the tropics and the economies of several countries [10]. The phenomenon has thus generated enormous public interest, and its analysis has attracted scientists from many fields. They include observationalists, theoreticians, and numerical modellers who have worked together very successfully during the last several years within the international Tropical Ocean Global Atmosphere (TOGA) project (198595). One aim has been to better understand ENSO by developing coupled ocean-atmosphere models.
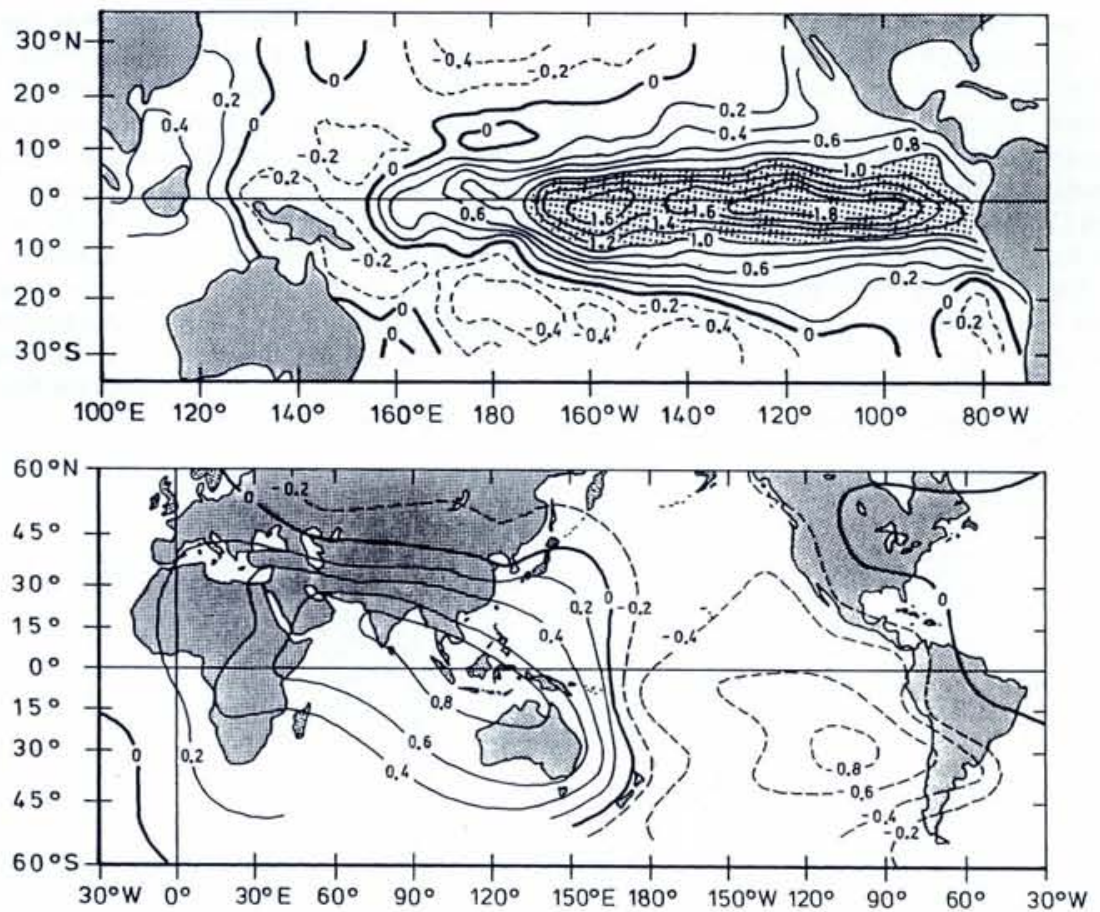

Fig. 1 - a, upper) A typical anomaly pattern for the tropical Pacific sea surface temperature associated with the El Niño phenomenon $\left(0.2^{\circ} \mathrm{C}\right.$ contour interval) [1]. $b$, middle) Spatial structure of the Southern Oscillation showing the global-scale nature of the phenomenon [2]. Shown is the correlation of annual pressure anomalies at Djakata (Indonesia) with all

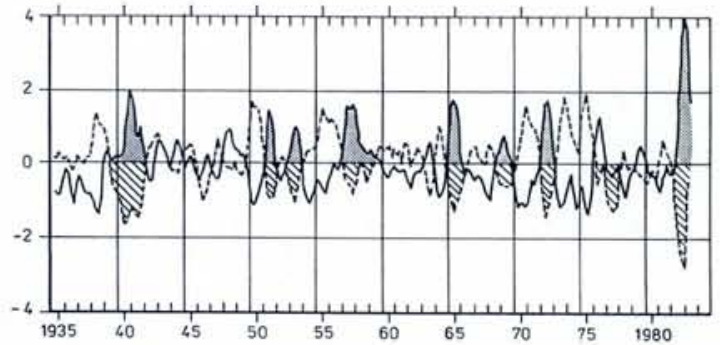
other locations ( 0.2 contour interval). c, lower) Time series of the Southern Oscillation Index (SOl; dashed line) which measures the atmospheric sea-level pressure gradient across the tropical Pacific basin and of the anomalous sea-surface temperature (SST) at Puerto Chicama in Peru (solid line) [3]. Both time series are normalized by their standard deviation. Shading indicates major ENSO warm phases (high SST; low SOI). 


\section{Going Beyond Bjerknes}

Current theory, in adopting a slightly more complex version of the interactions envisioned by Bjerknes, regards ENSO as originating from an instability of the coupled ocean-atmosphere system in the tropical Pacific. The long-term average sea surface temperature (SST) of the Pacific along the equator is characterized by a strong gradient, with temperatures of about $20^{\circ} \mathrm{C}$ in the eastern Pacific and of about $30^{\circ} \mathrm{C}$ in the western part. This temperature difference introduces an atmospheric circulation cell of the direct type (air rising over warmer surface layers) parallel to the equator which Bjerknes named the Walker Circulation, in honour of the discoverer of the Southern Oscillation. Within the Walker Circulation, air flows westward in the surface layers as part of the trade-wind system and is heated and supplied with moisture over the warm, western Pacific. The air then rises giving deep convection and heavy rainfall. It remains at upper levels for some time before descending over the relatively cold eastern part of the Pacific Ocean, thus completing the Walker Circulation.

The stress at the ocean's surface of the westward-flowing wind has a strong impact on the circulation of the ocean near the equator. Water is piled up in the west and a gradient in the sea level of about $400 \mathrm{~mm}$ is established across the Pacific. This gradient is compensated for by a slope in the thermocline (the interface separating the wellmixed, warm surface waters from the cold waters found at deeper levels), which tilts upward in the east. The change of sign of the Coriolis force due to the Earth's rotation at the equator means that the associated surface currents near the equator diverge and run poleward in both the northern and southern hemispheres. This divergence drives a narrow band of equatorial upwelling. The combination of upwelling and a

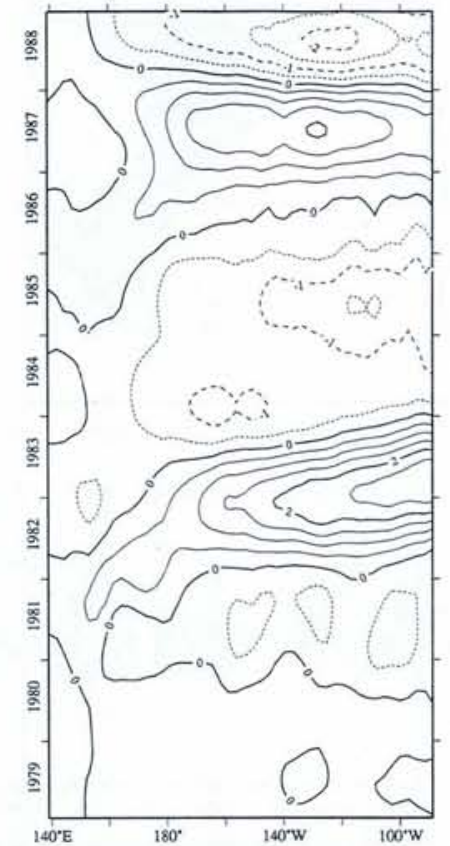

Fig. 2: - Time-longitude plot of observed anomalies along the equator during the period 197988 [12]: left) SST: $0.5^{\circ} \mathrm{C}$ contour interval; right) Heat content integrated above $275 \mathrm{~m}\left(100^{\circ} \mathrm{Cm}\right.$ contour interval). The data have been low-pass filtered to remove variability on time-scales smaller than 17 months.

\section{Effect on Major Rainfall Systems}

Droughts and flooding: during the El Niño phase of the EI Niño-Southern Oscillation, droughts are frequently observed in Southeast Asia and in parts of Australia, while on the other side of the Atlantic, excessive rainfall and flooding are experienced over parts of South America.

Rainfall variations: correlations of ENSO with the strength of the summer monsoon in India and with interannual variations of rainfall in the Sahel region have been demonstrated (e.g., see [5]).

Atmospheric circulation: atmospheric circulation outside the tropics is influenced by ENSO, primarily during winter (e.g., [6]). A characteristic long-range influence (called the Pacific/North America connection pattern by meteorologists) describing the response of the atmospheric winter circulation associated with the extremes of the ENSO cycle has been identified [7] and exploited for short-range climate predictions for the North Pacific/North American region [8].

Impact on European climate: a significant, although, weak response to ENSO over Europe has been found [9]. In periods such as 1982/3 when the El Niño is exceptionally pronounced, the air over central Europe in winter is unusually warm so the rainfall is higher than average. shallow thermocline leads to the relatively cold surface layers in the eastern Pacific, while the deep thermocline in the west is associated with a warm surface.

\section{Anomalies amplified}

A perturbation in either the Walker Circulation or the SST at the equator can be amplified by unstable air-sea interactions. Consider, for instance, a positive SST anomaly in the eastern equatorial Pacific. This anomaly reduces the east-west SST gradient and hence the strength of the Walker Circulation, resulting in weaker trade winds at the equator. The result is a deeper thermocline and reduced currents and upwelling, leading to higher SSTs in the eastern Pacific which reduces further the gradient of the SST. There is a positive feedback which can lead to instabilities in the mean state of the climate owing to interactions between the ocean and the Earth's atmosphere.

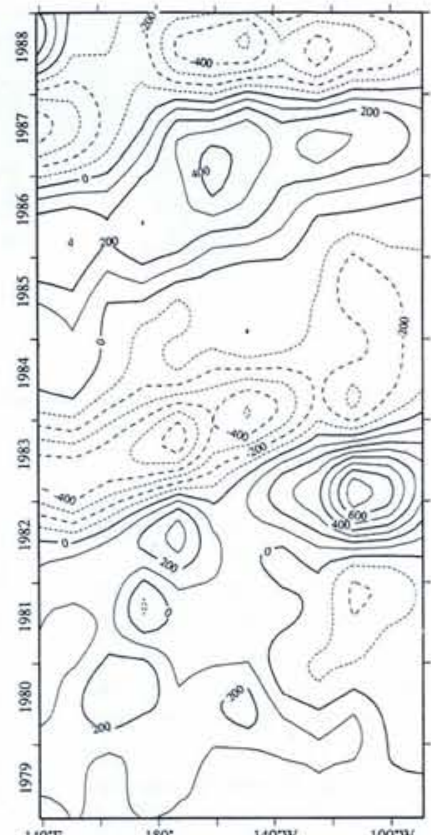

(n)

(1)

Between the heat content of the upper layers of the ocean on the one hand and the SST and the wind stress on the other there exists the phase differences needed to maintain an oscillation. The ocean is not in equilibrium with the atmosphere and carries information associated with past winds that permits continuous oscillation [11]. The phase differences can be seen clearly in Fig. 2 showing the evolution of the equatorial SST and upper ocean heat content as function of longitude and time, as derived from observations over 10 years. While the SST is dominated by a standing-wave component, the characteristic signature of the subsurface memory is reflected in the lead of the heat content anomalies in the western part relative to those in the eastern part. This behaviour is particularly prominent during the latter half of the record when the number of observations was increased considerably owing to the TOGA project.

\section{A delayed action oscillator}

The subsurface memory of the system can be related to ocean wave dynamics. The delayed action oscillator [13] is a conceptual model that provides a simple analogue. It illustrates very clearly the role played by the propagation of equatorial waves and their reflections at meridional boundaries corresponding to land masses (South America and Australia/Southeast Asia in the case of ENSO; see Fig. 3). Suppose that unstable air-sea interactions produce warm SST perturbations growing in the eastern Pacific together with perturbations, to the west of the SST perturbations, in the wind that is blowing eastward (perturbations are generally called anomalies by meteorologists). The effect of the eastward wind anomalies is to deepen the thermocline in the eastern part of the basin through downwelling waves that strengthen the EI Niño warming. These waves are called Kelvin waves and are essentially gravity waves. At the same time, the eastwardblowing winds force upwelling signals at the western edge of the wind anomalies and these signals propagate westward as socalled Rossby waves that push the thermocline upwards (for a Rossby wave, the restoring force is the north-south depen- 
Fig. 3-Schematic illustration of the delayed action oscillator scenario [14]. a, upper) Shown are the conditions during the warm (El Niño) phase of ENSO in the eastern Pacific. As the SST anomaly grows (corresponding to an increase in temperature in the shaded region), eastward flowing anomalies (small arrows) at the western edge of the SST anomaly excite upwelling which propagates westward as Rossby wave packets which have a maximum amplitude a few degrees north and south of the equator. They are reflected at the western boundary (Australia and Southeast Asia), and return as a Kelvin wave packet. The resulting oscillation period is the result of the superimposition of many free and forced wave modes. $b$, lower) Illustration showing how upwelling redistributes warm water, thereby reducing the gradient of the thermocline.

dence of the Coriolis force). The upwelling signal propagates to the western boundary, reflects as an upwelling signal propagating eastward in the form of a Kelvin wave packet, and reaches the growing warm SST anomaly in the eastern basin after a delay time. (Note that the SST is not affected in the western Pacific because of the deep thermocline in this region.) The result is that the warm SST anomaly is influenced both by local processes tending to make it grow, and by remote processes tending to oppose growth.

Eventually, the remote processes dominate and the warm anomaly stops growing, starts to cool, and the sequence of events is repeated, but with reversed signs, and the system moves into the cold (La Niña) phase of the ENSO cycle. So according to this model, the ENSO is based on self-sustained oscillations and its attractor can be described by a limit cycle - a periodic orbit in phase space (Fig. 4).

However, as discussed in a review of the theory of the ENSO [12], the delayed action oscillator scenario represents just one (albeit useful) limit in parameter space. The most realistic regime includes other processes independent from ocean-wave dynamics (such as those described by Hirst, Neelin, and Barnett et al. [16]. Furthermore,

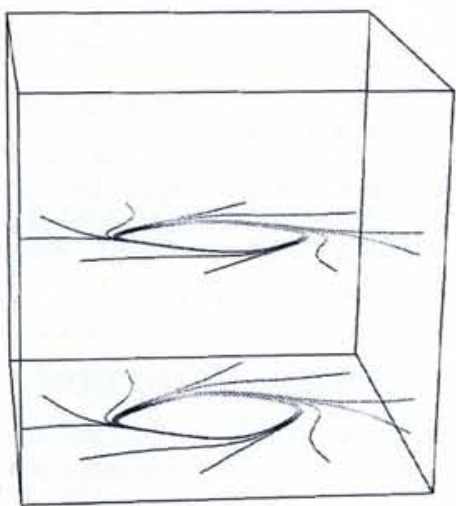

Fig. 4 - The ENSO attractor displayed in a low-dimensional phase space, as derived from 20 years of tropical Pacific surface and subsurface temperatures and zonal wind stresses [15]. Shown are 10 phase-space trajectories which converge onto a limit-cycle attractor. The curves at the bottom of the box represent a projected image on this plane. the real system is less regular than the theoretical models (Fig. 1c). The inclusion of both random forcing to account for the highfrequency variability of weather fluctuations and nonlinear interactions between different time-scales (especially between the annual cycle and the ENSO mode) are possible candidates for obtaining more irregular behaviour (e.g., [17]).

\section{Coupled models successful}

A hierarchy of coupled ocean-atmosphere models has been developed to study the dynamics of ENSO [18]. Conceptual and simple models (such as the delayed action oscillator model) are useful in gaining some insight into the fundamental dynamics of the coupled system, but they cannot be verified rigourously by observations. Intermediate coupled models usually consist of a sophisticated ocean model coupled to a simple atmosphere model. These models are realistic enough to be compared to observations, and simple enough to trace the basic physical mechanisms: they tend to simulate

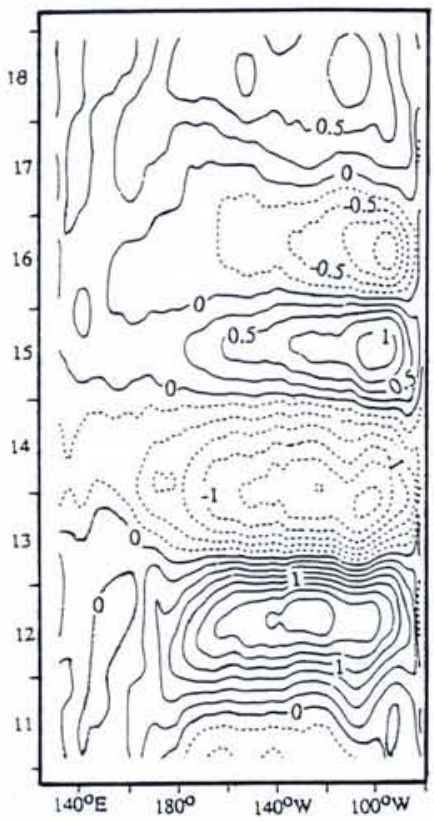

Fig. 5 - Time-longitude plot of anomalies along the equator from the coupled general circulation model of Philander et al. [21]. Left) SST, $0.25^{\circ} \mathrm{C}$ contour interval; right) Heat content integrated above $275 \mathrm{~m}, 50^{\circ} \mathrm{Cm}$ contour interval [12]. The data have been low-pass filtered to remove variability on time-scales smaller than 24 months. anomalies from a prescribed climatic state. One of the most successful is that of Zebiak and Cane [17] which has been used extensively to simulate and forecast the ENSO.

Coupled general circulation models (CGCMs) are the most complex, being based on a rather complete set of physical equations and designed to simulate the long-term average state of the climate and its variability. CGCMs should be compared closely to observations, but they often suffer from climate drift, with the model climatology departing from from the observed behaviour (e.g., [20]). Nevertheless, considerable progress has been made recently. Fig. 5 shows an example of the interannual variability simulated by one of the first CGCMs consisting of a high-resolution ocean model coupled to a coarse-resolution atmosphere model [21]. While the spectrum of interannual time-scales may not exactly match that observed (Fig. 2), the spatial form, with dominant standing-wave oscillations in the SST and subsurface phase lags, is reasonably close to what is found in Nature. Other CGCMs yield similar results, but with some variation to the spatial form (see, e.g., [22]). It seems that to simulate ENSO realistically, a high resolution in oceanic regions is required because equatorial waves of relatively small meridional scales contribute significantly to the oceanic memory.

\section{Predictability Achieved}

The quasi-periodic nature of the ENSO together with the theoretical considerations discussed above imply that a fairly high level of predictability. Several prediction schemes have been developed, including statistical and physical models [23]. The most successful schemes, the coupled ocean-atmosphere models, are able to predict ENSO behaviour up to even more than one year ahead of time. Fig. 6 plots the correlation between the observed and predicted SST anomalies averaged over the

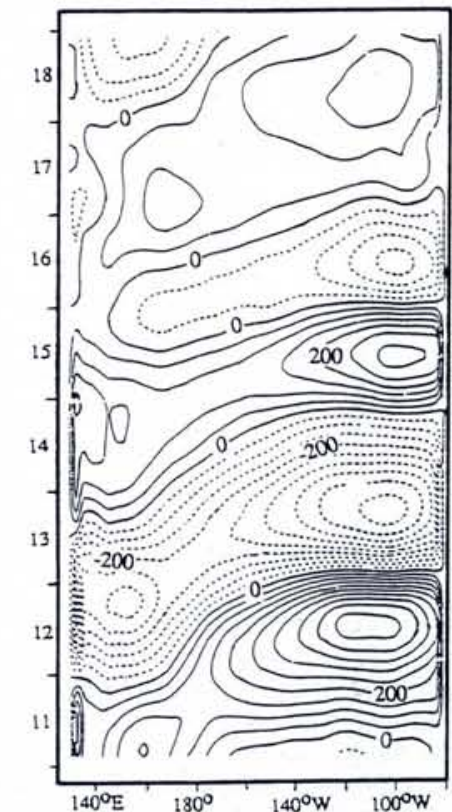

Europhys. News 25 (1994) 
eastern equatorial Pacific for the intermediate coupled model of Zebiak and Cane, the first coupled model used for forecasting the ENSO.

Most coupled models, including that of Zebiak and Cane, are limited to the tropical Pacific region and cannot be used directly to study the predictability of climate anomalies outside the Pacific or beyond the tropics. However, the forecast tropical Pacific SSTs can be used to determine the associated atmospheric response by feeding them into global atmospheric models. Barnett et al. [24] obtained encouraging global forecasts using this two-tiered approach. Forecasts were restricted to the winter season and major ENSO extremes. The cover illustration shows the correlation between the observed anomalies at a height (about 5 $\mathrm{km}$ ) corresponding to a mean atmospheric pressure of $500 \mathrm{hPa}$ with the forecasts for two seasons ahead. Significant correlations are found, both inside and outside the tropics. So various global coupled ocean-atmosphere models are currently being developed further to forecast simultaneously tropical and extra-tropical climate anomalies.

For lead times of a few months, the coupled models do not perform better than a persistence forecast, i.e., a forecast that assumes that the SST anomalies remain constant throughout the forecast period (see Fig. 6). This is because up to now ocean observations have not been used to initialize the coupled models. Instead, the observed wind stresses are used to initialize the ocean component. Errors in the forcing and the formulation of the model thus manifest themselves as considerable errors in the initial SST anomaly fields. Significant improvement of the forecasts at small lead times can be expected by assimilating in situ (e.g., [25]) and/or space observations, which are becoming increasingly available.

\section{Outlook Encouraging}

Much remains to be done in modelling the El Niño-Southern Oscillation. The phenomenon demonstrates, for instance, a pronounced variability over the time-scale of decades which needs to be explained (it might be related to variations in the circula-

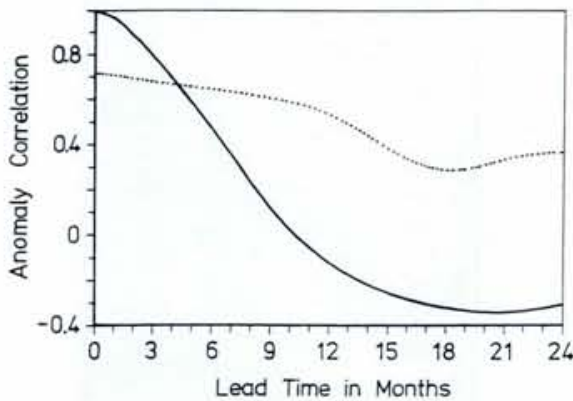

Fig. 6-The success rate of a series of predictions as a function of the lead time for forecasts using Ziebiak and Cane's intermediate coupled model (dotted line) compared with the rate obtained by assuming the persistence of anomalies [12]. The measure used was the correlation between the predicted and observed SST averaged over the region of the largest ENSO anomalies $\left(5^{\circ} \mathrm{N}-5^{\circ} \mathrm{S}\right.$; $\left.90^{\circ} \mathrm{W}-150^{\circ} \mathrm{W}\right)$ during $1972-91$.

\section{CLIVAR to Extend ENSO Studies}

There are some problems beyond the El Niño-Southern Oscillation which need to be addressed in the near future. Evidence exists, for instance, that tropical seasurface temperature (SST) anomalies in the Atlantic Ocean have a significant impact on the rainfall in Brazil, but the effect of Indian Ocean SST anomalies is still unclear. So the role of SST anomalies in the tropical oceans other than the Pacific in forcing tropical and extra-tropical climate anomalies must be better understood.

A systematic assessment of the predictability of climate anomalies at medium latitudes is pending (we note, however, that the situation in the mid-latitudes is unfavourable relative to the tropics because of the high noise level in these regions).

Meanwhile, the role of mid-latitudinal SST anomalies in forcing regional and global climate anomalies remains controversial; numerical experiments with coupled oceanatmosphere models will provide further insight.

Similarly, the impact of variations in other atmospheric boundary conditions such as soil moisture and sea ice needs investigation.

Most of these aspects will be covered by the World Climate Research Programme's International Climate Variability and Predictability (CLIVAR) project which begins in 1995 and lasts for 15 years.

tion of the oceans around the globe). Furthermore, particular periods in the past have been turned out to be unpredictable; the reasons need to be explored, and theoretical limits to predictability determined. Improved understanding of the interactions between ENSO and other phenomena and time-scales is also required. For instance, it is well established, that ENSO affects the monsoon in Asia, but it is unclear if the monsoon feeds back to ENSO. Another interesting question is whether or not ENSO is affected by anthropogenic climate change such as tropical deforestation or a possible greenhouse warming. Finally, the systems for forecasting ENSO are still at a rather low level of sophistication relative to numerical weather-prediction models. The initialization problem clearly needs to be addressed more carefully, and the first encouraging results are starting to emerge.

There are also related problems which will be addressed by a new international programme (see insert). In general, however, the ENSO phenomenon has had an influential effect on climate research, and a fruitful international collaboration between specialists in several fields has led to a reasonably advanced understanding. It stimulated the development of coupled ocean-atmosphere models and is providing them with a testbed which is relevant for global greenhouse warming. ENSO forecasts represents the first successful examples of short-range climate forecasting; they are currently conducted at several institutions for use by governments in several countries, notably those whose economies are affected.

[1] Rasmusson E.M. \& Carpenter T.H., Mon. Weather Rev. 10 (1982) 354

[2] Berlge H.P., K. Ned. Meteor. Inst. Meded. Verh. 69 (1967) 152.

[3] Rasmusson E.M., Oceanus 27 (1984) 5.

[4] Ropelewski C.F. \& Halpert M.S., J. Climate 2 (1989) 268.

[5] Shukla J. \& Paolino D.A., Mon. Weather Rev. 9 (1983) 1830; Folland C.K., Palmer T.N. \& Parker D.E., Nature 320 (1986) 602.

[6] Shukla J. \& Wallace J.M., J. Atmos. Sci. 40 (1983) 1613

[7] Wallace J.M. \& Gutzler D.S., Mon. Weather Rev. 109 (1981) 784.

[8] Barnett T.P. \& Preisendorfer R., Mon. Weather Rev. 115 (1987) 1825.
[9] Fraedrich K. \& Muller K., Int. J. Climate 10 (1992) 21.

[10] Oceanus 27, No. 2 (1994); Teleconnections Linking Worldwide Climate Anomalies, Eds.: M.H. Glantz, R.W. Katz \& N. Nicholls (Cambridge University Press) 1991

[11] Cane M.A. \& Sarachik E.S., J. Mar. Res. 39 (1981) 651; Chao Y. \& Philander S.G.H., TOGA Notes 3 (1991) 1.

[12] Neelin J.D., Latif M. \& Jin F.E., Ann. Rev. Fluid. Mech. 26 (1994) 617

[13] Battisti D.S. \& Hirst A.C., J. Atmos. Sci. 46 (1989) 1687; Craham N.E. \& White W.B., Science 240 (1988) 1293; Schopf P.S. \& Suarez M.J., J. Atmos. Sci. 45 (1988) 549; Suarez M.J. \& Schopf P.S., J. Atmos. Sci. 45 (1988) 3283.

[14] Sarachik E.S., in Climate-Ocean Interactions, Ed.: M.E. Schlesinger (Kluwer Academic Publishers) 1990.

[15] Grieger B. \& Latif M., Climate Dynamics, in press.

[16] Barnett T.P. et al., J. Climate 4 (1991) 487; Hirst A.C., J. Atmos. Sci. 43 (1986) 606; ibid., 45 (1988) 830; Neelin J.D., J. Atmos. Sci. 48 (1991) 584.

[17] Jin F., Neelin J.D. \& Ghil M., Science 264 (1994) 5155, p. 70; Latif M. \& Fltgel M., J. Geophys. Res. 96 C2 (1991) 2661; Tzippermann E. et al., Science 264 (1994) 5155, p. 72

[18] McCreary J.P. \& Anderson D.L.T., J. Geophys. Res. 112 (1991) 934.

[19] Zebiak S.E. \& Cane M.A., Mon. Weather Rev. 115 (1987) 2262

[20] Neelin J.D. et al., Climate Dynamics 7 (1992) 73.

[21] Philander S.G.H. et al., J. Climate 5 (1992) 308.

[22] Latif M. et al., J. Climate 6 (1993) 5; Nagai T et al. J. Climate 5 (1992) 1202.

[23] Barnett T.P. et al., Science 214 (1988) 192; Latif M. et al., Climate Dynamics 9 (1994) 167. [24] Barnett T.P. et al., Tellus 46A (1994) 381.

[25] Leetmaa A. \& Ji. M., Dyn. Atmos. Oceans. 13 (1988) 465 .

\section{COVER ILLUSTRATION}

Readers are asked not to use cover illustrations as primary reference sources. The figures are often scanned in and touched up by the printer, so while they are as accurate as can be expected they do not correspond exactly to original data. These remarks apply especially to this month's cover and to the shell corrections for nuclei reproduced in April 1994. 